\title{
FORMAÇÃO DE PROFESSORES: A QUE DIMENSÕES SE CONCEITUAM ${ }^{1}$
}

\section{Teachers' formation: in which dimensions they conceotualize themselves}

\author{
Paula Ledoux2 \\ Tadeu Oliver Gonçalves3
}

\section{RESUMO}

O presente artigo discute a formação de professores em suas dimensões e originou-se a partir dos estudos realizados para a elaboração da dissertação do curso de Mestrado em Educação em Ciências e Matemáticas, que investiga os saberes constituídos no processo de formação inicial de professores em serviço. A investigação foi realizada com professores-alunos do curso de Licenciatura Plena em Matemática da UFPA. A análise desses resultados teve como premissa a identificação desses saberes, a partir dos relatos feitos pelos professores-alunos sujeitos desta pesquisa. As dimensões da formação é um dos aspectos abordados nesta discussão por tratar-se de tema relevante na formação de professores. O conteúdo que deu origem a este texto está inserido no segundo capitulo, onde fazemos uma conversa com os teóricos que fundamentaram as discussões ao longo da construção da dissertação, baseados em estudos realizados por: Placco (1999), Bolzan (2002), Freire (1991), Gil - Perez (2001), Fusari (1999), Ponte (1992), Tardif, Lessard e Lahye (1991), Gauthier (1998), entre outros que discutem sobre mudanças, saberes e as dimensões da formação inicial e continuada.

Palavras-chave: Formação de professores, mudanças, saberes, dimensão.

\begin{abstract}
This article discuss the teachers' formation in their dimensions and was origined from the studies for the elaboration of a masters paper and investigate knowledge built in the process of inicial formation. The investigation happened with teachers - students of the mathematics course of UFPA. The analysis of this results had as a premise the identification of these knowledge, from what was related by the teachers - students of the research. The formation's dimensions is one of the aspects involved in this discussion, because it is a relevant theme in teachers' formation. The content that origined this text is insert in the second chapter, in

\footnotetext{
1 Este artigo é parte da pesquisa que realizamos para a construção de nossa dissertação de mestrado, no Programa de Pós-Graduação em Educação em Ciências e Matemáticas da UFPA, no Núcleo Pedagógico de Apoio ao Desenvolvimento Científico (NPADC), redigida sob a orientação do Prof. Dr. Renato Borges Guerra e co-orientação do Prof. Dr. Tadeu Oliver Gonçalves, intitulada: De Prático a Profissional da Matemática: Que Saberes se constituem em um processo de Formação Inicial de Professores em Serviço.

${ }^{2}$ Mestre em Educação em Ciências e Matemáticas, pela Universidade Federal do Pará, Brasil (2005). Professora Assistente da Universidade Federal do Pará, lotada no Campus Universitário de Castanhal. paulaledoux@ hotmail.com.br.

${ }^{3}$ Doutor em Educação pela Universidade Estadual de Campinas, Brasil(2000). Professor Adjunto IV da Universidade Federal do Pará , Brasil. tadeuoliver@yahoo.com.br.
} 
which is insered the studies made by Placco (1999), Bolzan (2002), Freire (1991), Gil - Perez (2001), Fusari (1999), Ponte (1992), Tardif, Lessard e Lahye (1991), Gauthier (1998), above others that discuss about changing, knowledge and the dimensions of continuous teachers' formation.

Keywords: teachers' formation, changes, knowledge, dimension.

\section{INTRODUÇÃO}

[...] o inacabado do ser ou da sua inconclusão é a própria experiência vital. Onde há vida, há inacabamento (FREIRE, 1991, p.50).

Fazer reflexões acerca da formação de professores envereda por um caminho que nos leva a investigar a seguinte questão: O que é formar?

No terreno dos desenhos que norteiam as ações no campo da formação docente, temos o ato de formar como um processo que proporciona referências e parâmetros que superam a visão dos paradigmas de uma única forma, e que oferece [...] um continente e uma matriz a partir dos quais algo possa vir a ser (FIGUEIREDO, 1996, p. 117) e esse formar favorece uma postura crítica diante das múltiplas interpretações e ações que têm sido desenvolvidas na formação de professores (PLACCO, 1999).

$\mathrm{Na}$ perspectiva de responder nossa indagação sobre o que é formar, derivam outras questões que vem se interpor: Formar em relação a quê? Em que dimensões a formação de um professor deve ser? A formação se dá em diferentes dimensões? Quais podem ser consideradas fundamentais para a formação do professor? As respostas a estas questões vão sempre ser relativas e provisórias, não há uma só visão a respeito do tema e nem deveria, formar não começa e nem termina com datas previstas, é um processo que vai estar sempre inacabado, assim como não existem dimensões determinantes na formação, pois a formação não é avaliada em sua extensão, em seu volume e sim em sua consistência, sua completude. Assim, todas as dimensões do formar, do aprender, são consideráveis quando se discute formação docente.

Para iniciar nossa discussão sobre as possíveis dimensões da formação docente, tomamos como referencia os estudos realizados por Placco (1999, pp. 26-28), que situa as possíveis dimensões de formar:

A dimensão técnico-científica: não há controvérsia sobre a necessidade de formar o professor do ponto de vista dos conhecimentos técnico-científicos relacionados à sua área. No entanto, há controvérsia quando se considera o atual progresso cientifico e a rapidez com que as mudanças ocorrem em diferentes campos.

A dimensão da formação continuada: se o profissional formado a partir da compreensão, explicitada anteriormente, não tiver possibilidade de continuar pesquisando, questionando sua área de conhecimento, buscando novas informações, analisando-as, incorporando-as à sua formação básica, o que ocorrerá?

A dimensão do trabalho coletivo e da construção coletiva do projeto pedagógico: ficam cada dia mais evidente a dificuldade e a ineficiência do trabalho isolado. É em torno de 
um projeto da escola, com claros objetivos de formação dos alunos e do cidadão que, professores, diretores e outros profissionais da educação devem-se congregar para um trabalho significativo junto aos alunos.

A dimensão dos saberes para ensinar: esta dimensão abrange diferentes ângulos, dentre os quais o conhecimento produzido pelo professor sobre os alunos (sua origem social, suas experiências prévias, seus conhecimentos anteriores, sua capacidade de aprender, sua inserção na sociedade, suas expectativas e necessidades), o conhecimento sobre a finalidade e utilização dos procedimentos didáticos (os mais úteis e eficazes para a realização da tarefa didática que devem desempenhar), o conhecimento sobre os aspectos efetivo-emocionais, os conhecimentos sobre os objetivos educacionais e seus compromissos como cidadão e profissional.

A dimensão crítico-reflexiva: há necessidade de ressaltar o desenvolvimento de reflexão metacognitiva, que implica conhecimento sobre o próprio funcionamento cognitivo pessoal, e de habilidade de auto-regulação deste funcionamento, fundamental para e em qualquer processo formativo.

A dimensão avaliativa: interpenetrando todas essas dimensões da formação, uma outra se destaca, referente à capacidade avaliativa do professor em relação a aspectos específicos de sua prática pedagógica ou a aspectos específicos estabelecidos ou valorizados pelo sistema ou pela escola em que trabalha.

Nas dimensões desenhadas por Placco (1999), figuram-se os professores-alunos ${ }^{4}$ protagonistas desta pesquisa que, mesmo sem ter a clareza, mesmo que intuitivamente tenham feito algumas rupturas com alguns conceitos construídos, a partir do senso comum e no processo de formação, foram sendo redimensionados com base nos conhecimentos técnicocientíficos apreendidos no interior da academia, possibilitando a reformulação do fazer prático, dos fins e dos objetivos na utilização dos procedimentos didáticos e de seu comprometimento profissional. Aqui se situa outra dimensão, a dimensão do prazer, o que à primeira vista parece ser uma dimensão pouco analítica, pois tendência a uma dimensão da subjetividade, contrapondo-se à objetividade imposta pelo paradigma da ciência moderna (CUNHA, 1995).

No período que estivemos realizando a pesquisa, já se observava através dos relatos dos professores-alunos, as mudanças quando identificavam com um pouco mais de clareza a ideia da prática reflexiva, envolvendo a perspectiva da produção do conhecimento, incorporando inclusive, as dimensões efetivas (querer fazer), quando no exercício do dia-a-dia da sala de aula, proporcionavam aos seus alunos, a oportunidade de fazer seus posicionamentos em relação à prática do professor.

Nesta perspectiva, a dimensão cognitiva (saber fazer) dominada pela polarização: conhecimento científico ou senso comum, que passa pela experiência do professor-aluno, está imbricada numa dimensão existencial, pois neste momento ele consegue refletir e perceber que os sujeitos da aprendizagem não só atuam no plano cognitivo, mas que redefinem uma visão de mundo e de sociedade.

Para Bolzan (2002, p. 151), a construção do conhecimento pedagógico compartilhado se organiza com variedade e riqueza e se apresenta sob quatro dimensões:

A dimensão do conhecimento teórico e conceitual: caracteriza-se pela epistemologia que fundamenta a prática pedagógica do professor;

\footnotetext{
${ }^{4}$ Os sujeitos da pesquisa são identificados como professores-alunos porque antes de serem alunos, são professores-leigos da rede estadual de ensino e estão fazendo Licenciatura Plena em Matemática no curso de formação inicial de professores em serviço. 
A dimensão da experiência prática: caracteriza-se pelas formas de intervenção do professor, durante a ação pedagógica;

A dimensão da reflexão: é caracterizada pelo pensar sobre as situações de ensino propostas;

A dimensão da transformação: que se caracteriza pelo processo de apropriação do conhecimento.

Nos relatos feitos pelos sujeitos desta investigação, a racionalidade moral-prática esteve presente sempre que os professores-alunos referiram-se à dimensão do compromisso com o trabalho docente e o envolvimento da dimensão social com o conhecimento acadêmico adquirido. A racionalidade estético-expressiva foi fortemente explicitada pela demonstração de prazer com o trabalho desenvolvido por eles, especialmente pela facilidade de poder expressar-se de forma subjetiva e pelas novas metodologias aplicadas, permitindo que o diálogo e a comunicação agora fizessem parte de suas práticas pedagógicas.

A dimensão política é pensada na essência de seu conceito, pois há que se considerar que esta dimensão fundamenta a própria condição humana, visto que o homem é naturalmente um animal político.

Essa dimensão, fundada na natureza humana, conduz necessariamente a outra dimensão, que pode ser considerada como uma das mais importantes - a dimensão ética. Esta fundamenta qualquer forma de organização da vida humana, pois todo processo civilizatório configura sua ordem e suas regras para o convívio numa sociedade civil. Entretanto, outra dimensão básica é fundamental nesse processo. É a dimensão da complexidade da formação de um cidadão que envolve assumir a responsabilidade para o bem estar de todos: saber ouvir, trabalhar em equipe, assumir lideranças, ter iniciativas que envolvam a comunidade.

Além das dimensões já referidas, outras são pontuais quando se discute formação. Estas estão presentes ao longo do processo de construção do fazer docente. A dimensão pessoal, onde os aspectos de ordem pessoal começam a tomar forma, ou seja, o professor faz uma nova leitura de seu entorno e outros valores morais são acrescentados. A dimensão histórica, o professor se redefinir como pessoa e como ser social. A dimensão acadêmica, a vivência no espaço da academia permite ao professor experienciar outros saberes. A dimensão profissional, quando o professor se percebe em seu contexto, especificamente quando o processo de formação é inicial, oportunizando o repensar a prática. Estas dimensões são visivelmente distintas. Porém, intrínsecas, interdependentes e complementares entre si.

Com base nas reflexões dessas dimensões, pelas quais podem e devem ser formados os professores, situamos que o formar vai além dos fundamentos teóricos repassados nas academias. Como nos dizem Feinman-Nemser, Buchmann (1987) e Zeichner (1995), (apud GONÇALVES e GONÇALVES, 2001, p. 108),

[...] o processo de aprender a ensinar começa muito antes dos alunos freqüentarem os cursos de formação de professores: por isso, temos de ter em conta as idéias anteriores e as regras que os alunos aliam à experiência e devemos ajudá-los a exteriorizá-las e elaborá-las segundo concepções mais apropriadas.

Fizemos algumas considerações acerca das dimensões que se situam no caminho da formação docente. Porém, outro aspecto há de ser considerado para mediar o fazer pedagógico - os saberes que se movimentam nesse processo. 
Para Gil - Pérez (2001, p. 38-55), o professor deve Saber analisar criticamente o "ensino tradicional", principalmente por professores em formação; deve também Saber preparar atividades capazes de gerar uma aprendizagem efetiva, que se manifesta como uma das necessidades formativas básicas dos professores; deve ainda Saber dirigir trabalho dos alunos, a elaboração das atividades que os alunos irão realizar exige um trabalho coletivo de inovação e pesquisa e por fim deve Saber avaliar, é possível que a avaliação seja um dos aspectos do processo ensino/aprendizagem, em que mais se faça necessária mudança didática.

Aos saberes desenhados por Gil - Perez (2001), somam-se os estudos realizados por Tardif, Lessard e Lahye (1991), que nos servem de alerta para o fato de que, quando se interroga professores sobre seus saberes eles tendem a valorizar o fato de que estes se constroem e são originados na prática cotidiana da profissão de professor e através dessa são validados. Portanto, estes acabam se constituindo nos fundamentos de sua competência, e

[...] é a partir deles que os professores julgam sua formação anterior ou sua formação ao longo da carreira. É igualmente a partir deles que julgam a pertinência ou realismo das reformas introduzidas nos programas e métodos. Enfim, é a partir dos saberes da experiência que os professores concebem os modelos de excelência profissional no interior da profissão (p. 227).

Não diferente de Tardif, Lessard e Lahye (1991), Therrien (1995) salienta o quanto os estudos sobre a formação do professor ainda persistem numa dissociação entre a formação e a prática cotidiana, não enfatizando a questão dos saberes que são mobilizados na prática, ou seja, os saberes da experiência. Esse saberes são transformados e passam a integrar a identidade do professor, constituindo-se em elemento fundamental nas práticas e decisões pedagógicas, sendo, assim, caracterizados como um saber original. Essa pluralidade de saberes que envolve os saberes da experiência é tida como central na competência profissional e é oriunda do cotidiano e do meio vivenciado pelo professor. Segundo o autor,

[...] esses saberes da experiência que se caracterizam por serem originados na prática cotidiana da profissão, sendo validados pela mesma, podem refletir tanto a dimensão da razão instrumental que implica num saber-fazer ou saber-agir tais como habilidades e técnicas que orientam a postura do sujeito, como a dimensão da razão interativa que permite supor, julgar, decidir, modificar e adaptar de acordo com os condicionamentos de situações complexas. (p. 3).

Conforme vimos acima, o saber docente se constitui de vários saberes provenientes de diferentes e variadas fontes. Assim, os processos de produção de saber e de formação docente podem ser considerados como complementares. Porém, todo saber implica em processo de aprendizagem e de formação que exige desenvolvimento e sistematização desse processo.

Entendemos que, sob essa concepção de formação, a relação dos saberes docentes construídos e/ou em construção, não se reduz a uma função de transmissão dos conhecimentos já constituídos, é preciso ver o saber docente como um saber plural. Nesta perspectiva, os quatro pilares citados no "Relatório para a Unesco da Comissão Internacional Sobre Educação para o Século XXI", no livro Educação: um tesouro a descobrir (Jacques Delors, 1998), pode ser tomado como dimensões do aprender para orientar o fazer da educação.

Aprender a conhecer - Prazer de compreender, descobrir, construir e reconstruir o conhecimento, curiosidade, autonomia, atenção. Inútil tentar conhecer tudo. Isso supõe uma cultura geral, o que não prejudica o domínio de certos assuntos especializados. Aprender a conhecer é mais do que aprender a aprender. Aprender mais linguagens e metodologias do que conteúdos, pois estes envelhecem rapidamente. Não basta aprender a conhecer. É preciso aprender a pensar, a pensar a realidade e não apenas "pensar pensamentos", pensar o já dito, o 
já feito, reproduzir o pensamento. É preciso pensar também o novo, reinventar o pensar, pensar e reinventar o futuro.

Aprender a fazer - É indissociável do aprender a conhecer. A substituição de certas atividades humanas por máquinas acentuou o caráter cognitivo do fazer. O fazer deixou de ser puramente instrumental. Nesse sentido, vale mais hoje a competência pessoal que torna a pessoa apta a enfrentar novas situações de emprego, mas apta a trabalhar em equipe, do que a pura qualificação profissional. Hoje, o importante na formação do trabalhador, também do trabalhador em educação, é saber trabalhar coletivamente, ter iniciativa, gostar do risco, ter intuição, saber comunicar-se, saber resolver conflitos, ter estabilidade emocional. Essas são, acima de tudo, qualidades humanas que se manifestam nas relações interpessoais mantidas no trabalho. A flexibilidade é essencial. Existem hoje perto de 11 mil funções na sociedade contra aproximadamente 60 profissões oferecidas pelas universidades. Como as profissões evoluem muito rapidamente, não basta preparar-se profissionalmente para um trabalho.

Aprender a viver juntos - a viver com os outros. Compreender o outro, desenvolver a percepção da interdependência, da não-violência, administrar conflitos. Descobrir o outro, participar em projetos comuns. Ter prazer no esforço comum. Participar de projetos de cooperação. Essa é a tendência. No Brasil, como exemplo desta tendência, pode-se citar a inclusão de temas/eixos transversais (ética, ecologia, cidadania, saúde, diversidade cultural) nos Parâmetros Curriculares Nacionais, que exigem equipes interdisciplinares e trabalho em projetos comuns.

Aprender a ser - Desenvolvimento integral da pessoa: inteligência, sensibilidade, sentido ético e estético, responsabilidade pessoal, espiritualidade, pensamento autônomo e crítico, imaginação, criatividade, iniciativa. Para isso não se deve negligenciar nenhuma das potencialidades de cada indivíduo. A aprendizagem não pode ser apenas lógico-matemática e linguística. Precisa ser integral.

Esse complexo processo de construção da formação docente é sempre tema de pauta de estudos realizados por muitos teóricos e surge no momento em que o profissional da educação inicia sua formação. Para Ponte (1992), a formação inicial é o movimento que ocorre de fora para dentro. Concordamos com o autor do ponto de vista do meio em que o professor está inserido. Esse contexto servirá de estímulo ou desestímulo, para que o professor vá à busca dessa formação. Porém, quando esse professor vive num contexto onde é constantemente expropriado das condições necessárias à produção de seu trabalho, com baixos salários, a não valorização da formação e o dilema da progressão funcional, o peso maior para que haja esse movimento, tem que ser de dentro para fora, pois nem sempre essa busca pela formação depende exclusivamente do professor. Outros fatores (econômicos, sócio-culturais e políticos) contribuem para reforçar a presença e/ou a ausência desse professor nos cursos de formação inicial. Esses profissionais vivem dentro de um quadro de tensões, situados entre fazer uma formação inicial ou acomodar-se.

Os atores sociais que participaram deste estudo, na verdade, deixaram-nos uma grande lição provando que são capazes muito mais do que aceitar as coisas passivamente ou acomodar-se quando ingressaram no curso de formação inicial de professores em serviço, mostrando uma força interior muito grande de lutar, de transformar suas realidades, de provocar mudanças, enfrentando todas as dificuldades, passaram quatro longos anos fazendo uma formação inicial, desmistificando o papel de professor leigo, tornando-se professores Licenciados Plenos em Matemática. E para que essas mudanças ocorram a partir da formação inicial, e para obter-se os resultados considerados desejáveis, deve-se atentar para o envolvimento, a adoção e a participação do professor-aluno como principal sujeito desse processo. 
Um outro aspecto que consideramos relevante na construção da formação inicial de professores é o que defende Conney (1985), ao afirmar que o conhecimento do professor é a soma do conhecimento do senso comum ao produto de investigação disciplinada. Concordamos com o autor, pois consideramos o contexto onde se desenvolvem as atividades do professor que se considera como "[...] uma parte integral desta conceitualização de desenvolvimento", (ib id p. 10), fator preponderante para que esse conhecimento aconteça se intensifique e se estenda de forma mais ampliada.

Para esse autor, o contexto onde ocorrem as atividades exercidas pelo professor irá determinar o processo de adaptação, de reflexão e o posicionamento que irá tomar frente às pressões que lhes são colocadas no contexto de sala de aula. $\mathrm{O}$ autor nos chama a atenção sobre a possibilidade de o professor vir a adquirir habilidades para fazer reflexões acerca de suas ações, de se auto-avaliar, de viver o conhecimento novo, de trocar experiências.

Em relação a estes aspectos, o autor comenta:

[...] é importante para compreendermos as lutas e tensões que os professores experenciam assim como eles se esforçam para serem agentes adaptativos e compreenderem o que constitui progresso durante esse processo (COONEY, 1985, p. 12).

A contribuição de Conney (1985) foi significativa para o entendimento do desenvolvimento profissional do professor que se constrói a partir do conhecimento do senso comum que é a base para sua formação inicial e prossegue ao longo de uma formação continuada e, a partir dessa formação inicial, o professor poderá vir a ser mais flexível e se adaptar mais facilmente ao contexto em que atua.

A formação não se faz de forma isolada, assim como as pessoas não são compartimentos estanques. Portanto, a formação deve ser contínua ou continuada, pois não existe uma delimitação de onde começa e onde termina a formação. Esta se faz do/no alargamento da construção de identidades, conceitos, valores, de forma corporativa nos espaços de atuação pessoal, social, política, cultural e profissional, ou seja, [...] o ideal é que a formação contínua ocorra num processo articulado fora e dentro da escola (FUSARI, 1999, p. 19).

A formação continuada deve ser estimulada, não só no âmbito da escola, mas em todos os segmentos onde haja espaço para se construir conhecimentos. Além do saber adquirido nesse momento de troca, é preciso saber ouvir, respeitar e valorizar o profissional da educação. É preciso, ainda valorizar e socializar os saberes que emergem de sua experiência, proporcionando nessa troca a possibilidade da superação das dificuldades.

As reivindicações por melhorias nas condições de formação de professores têm sido luta constante de profissionais que desejam avançar em uma formação que lhes possibilite melhorar sua ação pedagógica, que lhes dê suporte para desenvolver atividades docentes satisfatórias. Porém, a formação, seja inicial ou continuada, só será levada a sério, quando ela for encarada como valor condicional para o desenvolvimento profissional dos trabalhadores em educação. No entanto, não há aqui nenhuma pretensão de "[...] relegar a formação de um professor exclusivamente à responsabilidade do Estado, cada profissional deve ser responsável por seu desenvolvimento pessoal e profissional, cabe a ele o direcionamento, o discernimento e a decisão de que caminhos percorrer" (FUSARI, 1999, p. 23).

Todos os sujeitos desta pesquisa que fazem o curso de formação inicial atuam no Ensino Fundamental e o que se constata é que estes possuem crenças e imagens anteriores que os acompanham ao longo de sua formação; considerando que os mesmos têm anos de prática de sala de aula e considerando ainda que essa prática se desenvolva num espaço real, com 
pessoas reais, com situações reais. Isto nos leva a concluir que estes profissionais já agregam saberes e que essa prática se dá em meio as mais variadas dimensões, mesmo que estes não consigam identificar e/ou dimensionar quanto, quando e como isso ocorre.

\section{INDÍCIOS DE UMA CONCLUSÃO}

Este estudo preliminar nos leva a perceber que a investigação dessa temática tem possibilitado identificar um percurso de pesquisa relacionado aos saberes, às dimensões e à formação de professores, desenvolvido com características próprias. De certa forma, o repensar a concepção da formação dos professores, que até há pouco tempo objetivava a capacitação destes, através da transmissão do conhecimento, a fim de que "aprendessem" a atuar eficazmente na sala de aula, vem sendo substituído pela abordagem de analisar como essa formação se dá em que dimensões e que saberes são construídos na relação entre o aprender e o fazer pedagógico.

Considerando que a tarefa do professor tem por característica o trabalho interativo, Gauthier (1998) enfatiza a dificuldade de trabalhar com os saberes formalizados. O autor sugere que as pesquisas sobre o saber da Ação Pedagógica poderiam contribuir para o aperfeiçoamento da prática docente e formação de professores, considerando, além dos conhecimentos científicos (provenientes da pesquisa acadêmica), o saber nascido da prática, opondo-se aos estudos concentrados na separação entre formação e prática cotidiana, que nos anos 80 estavam no cerne das investigações, destacando a questão técnica e política do trabalho pedagógico.

Apesar da existência de estudos realizados sobre a temática, ainda há carência de pesquisas empíricas que possibilitem responder alguns questionamentos, dentre os quais destacamos: como os saberes teóricos são transformados em saberes práticos? O saber que se constrói na vivencia prática tem maior relevância sobre os demais saberes? As dimensões se constituem como regras no ato de formar? Essas e outras questões são pertinentes quando se investiga a formação docente na perspectiva de construir caminhos para a melhoria do fazer pedagógico.

O que aqui foi pontuado não nos permite concluir, mas finalizar este texto considerando que o que ficou deste estudo é a certeza de que a educação como prática social é produtora do saber da experiência, que somados ao saber fazer, aqui entendido como dimensão operacional do conceito, incidirá, na redução do pensamento mecânico dos futuros professores no fazer pedagógico e como consequiência, tem-se uma formação onde a capacidade de pensar está concebida nos modelos de excelência profissional no interior de sua profissão.

\section{REFERÊNCIAS}

BOLZAN, Dóris Pires Veiga. Formação de Professores: Compartilhando e reconstruindo conhecimentos. Porto Alegre, Mediação, 2002.

CONNEY, T. (1985), A beginning teacher's view of problem solving. Journal for Research in Mathematics Educacion, v. 16.

CUNHA, M.V.A. Educação dos Educadores: da escola nova à escola de hoje. Campinas, Mercado das Letras, 1995.

DELORS, Jaques. Relatório para a UNESCO da Comissão Internacional sobre Educação para o Século XX. Cortez, 1996. 
FIGUEIREDO, Luiz Cláudio. Revisitando as psicologias. Petrópolis, Vozes, 1996.

FREIRE, Paulo. A Educação na cidade. São Paulo: Cortez Editora, 1991.

FUSARI José Cerchi. Formação Continuada de Educadores na Escola e em outras situações. In Coordenador Pedagógico e Formação Docente. São Paulo, Loyola, 1999.

GAUTHIER, Clermort. Por uma Teoria da Pedagogia: pesquisas contemporâneas sobre o saber docente. Ijuí, RS, Unijuí,1998.

GONÇALVES, T. V. e GONÇALVES, T.O. Reflexões sobre uma prática docente situada: buscando novas perspectivas para a formação de professores. In Cartografia do trabalho docente (Org.) Corinta M. G. Geraldi; Dario Fiorentini e Elisabeth Pereira - Mercado das Letras: Campinas, SP,1998.

GONÇALVES, T. O. A Formação e desenvolvimento profissional de formadores de professores: o caso dos professores de Matemática. Campinas, SP. 2000.

PERES, G. (1995). O pensamento prático do professor - a formação do professor como profissional reflexivo, in: NÓVOA, Antonio (org.) . Lisboa: Dom Quixote.

. Competência e compromisso político na formação do professor de matemática. Temas e Debates (Blumenau), SBEM, n7, 1995.

PLACCO, Vera Maria Nigro de Souza. A Formação do Professor: Reflexões, Desafios, Perspectivas. In. Coordenador Pedagógico e Formação Docente. São Paulo, Loyola, 1999.

PONTE, J. da P. Concepções dos professores de matemática e processo de formação. Browr, M. et AL. In Educação Matemática: temas de investigação. Lisboa. Instituto de Inovação Educacional, 1992.

TARDIF, M., LESSARD, C., LAHAYE,L. Os Professores Face ao Saber: Esboço de uma Problemática do Saber Docente. Teoria e Educação, nº. 4. Porto Alegre: Pannonica, 1991.

TARDIF, M. Saberes profissionais dos professores e conhecimentos universitários. Rio de Janeiro: PUC, 1999.

THERRIEN, J. Uma abordagem para o estudo do saber da experiência das práticas educativas. In: Anais da 18a Anped, 1995 (disq.).

ZEICHNER, Kenneth. Para além da divisão entre professor pesquisador e pesquisador acadêmico. Cartografia do Trabalho Docente: professor (a) pesquisador (a). Geraldi. G.; Fiorentini D.; Pereira, E.M.A. (Orgs). Campinas, SP. ALB.1998. 